\title{
Interview with Taira Nishizawa
}

\author{
Andrew Barrie
}

Since opening his Tokyo studio in 1993, Taira Nishizawa has established himself as a leading figure among his generation of Japanese architects. Nishizawa's work, which ranges from small houses to large sports facilities and makes particular use of innovative timber structures, has attracted numerous awards, including the prestigious Japan Institute of Architects Young Architect of the Year Award in 2005, the Architectural Review Emerging Architecture Award, and selection by Architectural Record as one of the world's 10 "Design Vanguard” architects.

A practitioner, academic and critic, Nishizawa teaches at a number of universities in Tokyo and has lectured and exhibited internationally. His work has been the subject of two monographs: Taira Nishizawa 1994-2004 (2004) and Taira Nishizawa: Wooden Works 2004-2010 (2011).

Nishizawa lectured in Auckland as part of The University of Auckland School of Architecture \& Planning's annual Communiqué lecture series. Supported by NZ Wood, he also lectured in Wellington and Christchurch. On May 24, 2012 he gave a seminar to students at The University of Auckland School of Architecture \& Planning, of which this text is an edited transcript.

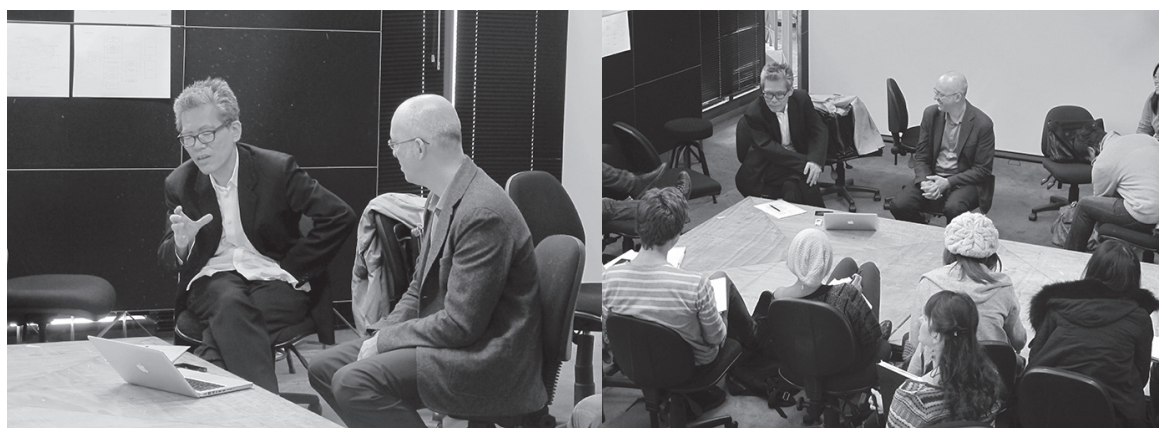

Barrie [to the audience]: During my student days, it struck me that it wasn't terribly helpful to learn how to design exceptional buildings like museums or concert halls. What I needed to know was what to do next - how to use my time at university, how to land a job, how to get established as a young architect. It's often difficult to learn about the early days of the architects we're interested in, so the intention of this seminar is to carry on the series of interviews we've done with architects focusing on their youth, and to ask Nishizawa-san what advice he has for those starting out on their architecture careers.

Barrie [to Nishizawa]: When did you decide to become an architect? What influenced this decision? Any particular architects or buildings?

Nishizawa: Actually, I haven't decided yet. [Laughs] Maybe around the time I turned 40, I realised I was no longer able to do any other type of job. That was my final decision. During my high school days, I was kind of a "small genius" in mathematics. I really loved maths. Other science subjects like physics and chemistry
Taira Nishizawa and Andrew Barrie in conversation, The University of Auckland, School of Architecture and Planning, 2012. [Photo: Melanie Pau] 
bored me - they weren't creative enough. For me, maths was the most creative field among human intellectual endeavours. Then I met a great "small genius" he was one of my high school classmates. I realised then that I wasn't enough of a genius, and changed my direction. Until then, I hadn't had any understanding or knowledge of architecture, but in comparison to physics or information science or chemistry it sounded a little bit interesting, so I decided to study architecture. I met a certain Japanese professor called Kazuo Shinohara. He'd actually switched his career from mathematics to architecture in his early 20s. I was surprised to hear of someone who'd made such a conversion. After meeting him, I started studying architecture seriously.

Barrie: So you met Shinohara at university?

Nishizawa: Yes, when I was 19 years old.

Barrie: When you'd already started studying mathematics?

Nishizawa: I stopped dreaming about maths, and began to concentrate on architecture. I was lucky because Shinohara was very famous in Japan. He'd built many beautiful small houses. He was not modernist - he was anti-modern - but his houses were beautiful and he had a certain kind of charisma. Shinohara was, for instance, a great idol for Toyo Ito and Kazuyo Sejima. He was a very influential and important person. When I was studying architecture under him, I didn't have much knowledge but I knew that this opportunity might be important for my life. This was during his last three years before retirement from the University, so he wasn't serious about giving reviews or lectures to his students, but I wanted to talk to him about his thoughts about architecture. I wanted to check out his performance. I thought about how Shinohara was old and must always go to the bathroom. So... I always waited for him in the bathroom at the university.

In the mornings, I didn't go to the studio but to the bathroom on his floor. I would sit on the toilet and read his books. [Laughs] When he came in, I'd say, "Good morning, Professor. What do you think about modernism?"

Barrie: You had conversations over the wall of the toilet cubicle?

Nishizawa: Sometimes. [Laughs] I'd ask, for instance, "What do you think about Aldo Rossi?” [Laughs] But you students - don’t do that!

Barrie: As a student, you were in Shinohara’s laboratory?

Nishizawa: Yes, the lab of Shinohara and Kazunari Sakamoto.

Barrie: You were taught by them both?

Nishizawa: Yes, Shinohara was a famous architect so he invited important Japanese architects such as Fumihiko Maki, Yoshio Taniguchi, Arata Isozaki, and Shiro Kuramata to give lectures. I was lucky.

Barrie: Were there any particular experiences during the design classes that were important for you?

Nishizawa: The most impressive thing was that we were always reviewed by three architects - Shinohara, Sakamoto and a visitor such as Maki or Isozaki. These 
three guys would give us comments that were different - absolutely different! It was so confusing, but it was interesting. I thought it worthy of really thinking about. That was a good experience.

Barrie: When you graduated, how did you go about getting a job?

Nishizawa: That was during the middle of the 1980s. During the mid-80s, Japan was in the midst of an economic bubble, and in those days we were rich! So most of my friends went to big architecture firms such as Takenaka or Kaijima, but I didn't want to go in that direction. I wanted to learn more. I wanted to go to a small architecture studio to learn about how to design and how to control a construction site. When I was 22 years old, during my last year at university, I read a certain interview between Shinohara and a publisher. The magazine wasn't a normal architectural journal but a construction company magazine. Shinohara's answers used the specific idioms of Japanese construction sites, and I couldn't understand any of it. I discovered that I needed to learn how to control and to communicate with carpenters, and so on. If I went to a big firm, that would be difficult. You can learn about the management of people - designers, consultants, and so on - but you can't talk directly to builders or craftsmen.

In those days, Toyo Ito and Sakamoto were Shinohara's supporters, but they were almost the same age as I am now - around 45 or 46 years old. This was the time of the economic boom, so their studios were already too big - they employed more than 10 or 12 people. I thought that would make it difficult to learn quickly and directly as there were many experienced senior staff. In such offices, you must work for a few years before managing a project. So, I tried to find someone from a younger generation. Kei-ichi Irie is about 10 years older than me and had studied in Shinohara's laboratory. I asked many of my Shinohara laboratory senpai who the best young architect was from our lab.

Barrie: To explain for the students - a senpai is an older student of the same professor as you. They're a kind of classmate, but even if you've never met them they are your senpai.

Nishizawa: Everyone suggested Irie, so I went to his office and spent seven years there. I was lucky. I was the studio's first member of staff - the rest were three or four foreigners - so I could be a project leader. It was a good time for Japan's economy, so there was lots of work, lots of chances to build. I gained good experience with every type of building - private houses, public projects, huge private housing developments, private clients, huge companies, government. Everything except cheap construction and poor clients! [Laughs]

Barrie: So what were your important memories working from that office? What did you learn?

Nishizawa: My first goal was to learn how to draw sectional details. To me, sectional details look fantastic, but at university we'd traced them. We couldn't learn enough to think about or to create new types of sectional detail. Our education was inadequate for learning how to protect against rain and moisture, or how to calculate structures. So, my first goal was to learn to draw those details, which I spent one or two years doing. We didn't have computers, faxes, or copy machines so we had to use our hands. Always. I drew so much, every day ... 
Nishizawa: The biggest reason was that I'd experienced everything, meaning I'd experienced every situation and type of client. So I asked Irie to let me leave his studio. That was the day the Japanese economic crisis occurred. That was when I realised that the only thing I hadn't experienced in Irie's studio was a cheap project for a poor client. After establishing my own office I had to begin with cheap projects and poor clients. That was unexpected. [Laughs]

Barrie: So, you already had a project to work on when you left?

Nishizawa: I set up my office first, and then started meeting with people in order to get jobs. My first client was a good friend of my sister. It was a small private house.

Barrie: Was this process of setting up on your own and doing small houses common in Japan at the time?

Nishizawa: Yes, the small private house has always been important for young architects establishing their own office.

Barrie: A few years earlier it had been very easy for young architects. After the economic bubble burst, it became very difficult. How did you feel about that?

Nishizawa: My goal was not to make money but to keep thinking about architecture, so I didn't take the economic situation seriously. I felt as long as they were building something somewhere in the world, there was no problem. As long as they were building, they'd require new ideas to keep going. Basically, I was very optimistic.

Barrie: Did you feel that the work you were doing was moving with the times, or trying to react or criticise the architecture of the time?

Nishizawa: I belong to a certain generation in the Japanese architectural world. The generation just older than us were very commercial architects such as Kengo Kuma, Kazuyo Sejima, and Jun Aoki. Their work is nice, but it wasn't enough for me. For me, architecture is more frustrating. It has huge capacity to control everything, every aspect of the environment for the humans and for all other creatures. But these older folk always concentrated on small, aesthetic aspects of space. I wasn't strongly critical of them; it was just that they weren't interesting enough. I always thought, "Let's be different."

Barrie: What was your relationship with other architects in your generation? When Toyo Ito was here, he said one of his most important experiences was to meet with his friends to drink and talk.

Nishizawa: One of my classmates was Yoshiharu Tsukamoto of Atelier Bow-Wow. Tsukamoto is a nice guy. He's far from intellectual; he's an activist, going off to every possible place. His character is very interesting for me. We are good friends. Also, I have a brother named Ryue who's two years younger than me. He collaborates with Kazuyo Sejima - actually, I recommended him to Sejima. Mark Dytham came to Japan after just graduation following England's economic crisis in the '80s. He's also an old friend.

Barrie: At that time, were you interested in collaborating with those colleagues? Or just talking? 
Nishizawa: No, not collaborating. Most of the important cultural trends happen not around one person but between two people. Thinking about rock musicians, Paul McCartney and John Lennon were a pair. They began something together without McCartney, Lennon wouldn't have done anything. At the beginning of classicism, Brunelleschi had a good friend when he shifted from the Gothic style. He and his friend Donatello, a sculptor, suddenly became fascinated with ancient buildings and talked creatively about them. Finally, they escaped the guilds of Florence and went to Rome to study the ancient ruins. So Classicism began not with one person but two people. If Brunelleschi hadn't had Donatello, he wouldn't have done anything. Of course, Lennon and Brunelleschi had great talent, but talent isn't enough to begin something. If you have a good, deep friend, what you're thinking can be something of a reality between you. We need deep friends to think and to talk with.

Barrie: Do you have any advice for students who are just beginning to start their architectural studies?

Nishizawa: Stop clicking!! On the computer. You're better to use your hands. You have to! Every time. If you write or draw something - use your hands every time. This is the biggest difference between apes and humans. It's a very important influence on your brain. I've never met architects who just click, but I've met many who'll grab a pencil or draw with a pen.

Barrie: Mark Dytham loves his Apple products. He has an iPhone in one hand, a laptop in the other, and operates his iPad with his knees. [Laughs]

Nishizawa: I mean, you should control it. You should know how to use these instruments and tools, but just clicking is dangerous. You lose something. You must use your hands at the same time as clicking.

Barrie: I remember being very shocked when I started at Toyo Ito's office. His reputation was as the "architect of the electronic age", but he received email from his secretary in printed-out form. He'd then write the answer on the bottom in pencil and give it back to her. When designing, the staff would make a simple paper model and draw a diagram using a really fat pen - not a beautiful drawing, but something basic and simple so that the concept was really clear. I remember being shocked at this. We had computers, of course. I'd expected a very high-tech office but it was actually quite a primitive system...

Nishizawa: I think human beings are very weak against the influence of tools. If you use a mobile phone, you can't remember telephone numbers any more. It becomes a kind of "outside brain". So you can use new stuff, of course, but you'd better control it. Which part of your brain is outside and which part is inside is something you must control. Don't outsource everything. [Laughs]

Student: I've noticed a very progressive thickening of the roof and wall in your later wooden buildings. It seems to be quite progressive, from $400 \mathrm{~mm}$ at the Itabashi House to $760 \mathrm{~mm}$ at Church Sun-Pu. Was that multi-layering deliberate?

Nishizawa: It just happened. When I was designing the Itabashi House, I realised that if I used a thicker wall and roof, I could control the various qualities of the space. So after that, I began to concentrate on that thickness, its performance, or the way it influences the relationship between inside and outside. The Church 
Sun-Pu required specific spatial qualities. Just thinking functionally about a church, it's not much different from a classroom. But the space must feel very different, so I needed a strategy to control that environment directly. I manipulated the performance of the external walls and roof to control the light and sound conditions, which are what distinguishes a church from a normal classroom or meeting place.

I'm always thinking about the natural environment. That is the big rival for architects. There are so many different varieties or types of environment in the natural world, but in comparison, within architecture there isn't sufficient variety. We should create different types of space in our buildings.

Student: Another young Japanese architect, Hiroshi Sambuichi, has a similar interest in the natural environment, but at a greater scale. How do you compare yourself to him, in terms of bringing the climate into your buildings?

Nishizawa: He is a nice guy. [Laughs] I like his personality. I like his work better than SANAA's because he sometimes alters his style to incorporate new things. Normally, an established architect has a defined style, but they then struggle to do anything outside of that. Selling your style is an effective way to make money, but it's the end of thinking or developing ideas. Sambuichi's style is not stable - sometimes he alters it or makes a mistake. It's a quality of leading architects not to have a style. So watch out!

I remember when I was 21 years old, in my third year of studying architecture. I was at the architecture library reading a French magazine that showed my professor Kazuo Shinohara's recent work. He sometimes changed his style drastically. It was the first time I'd seen his "last style" in a magazine. I couldn't read the French exactly - just the title and the architect's name. The model looked like his work, but it was quite different from what I'd known until then. I felt kind of scared. It was the moment when I understood how a living architect works. Living architects change day by day. Until then, all I'd known about were dead architects. We'd studied Le Corbusier, for instance, but he was dead so we knew everything, every style. But if you lived with Le Corbusier, he was always changing his style and you'd always feel scared. Well, not always, but he changed his style drastically several times. Can you imagine how you'd feel living at that time, in the 1940s or 1950s? You might feel some horror. That's a living architect. As a new architect, style is a little bit dangerous. Living architects don't care about style. They just care about how to keep going, how to reach out, how to extend the capacity of architecture.

Student: Where do you find inspiration?

Nishizawa: From nature. Nature is fascinating. The ability of artists can be compared with the performance of nature. I always feel jealous towards nature. It's a very important inspiration.

Barrie: So you're interested in outdoor activities such as hiking or skiing?

Nishizawa: No, I don't like those kinds of activities. [Laughs] But I mean what is happening in the natural elements - the effect of light, for instance. Even in the city, you can find many types of light and sound effects - noise, wind, humidity, everything. Those are all important for the space or environment. If we can gain enough control of them, we can create different types of space. Those kinds of natural qualities are interesting. 

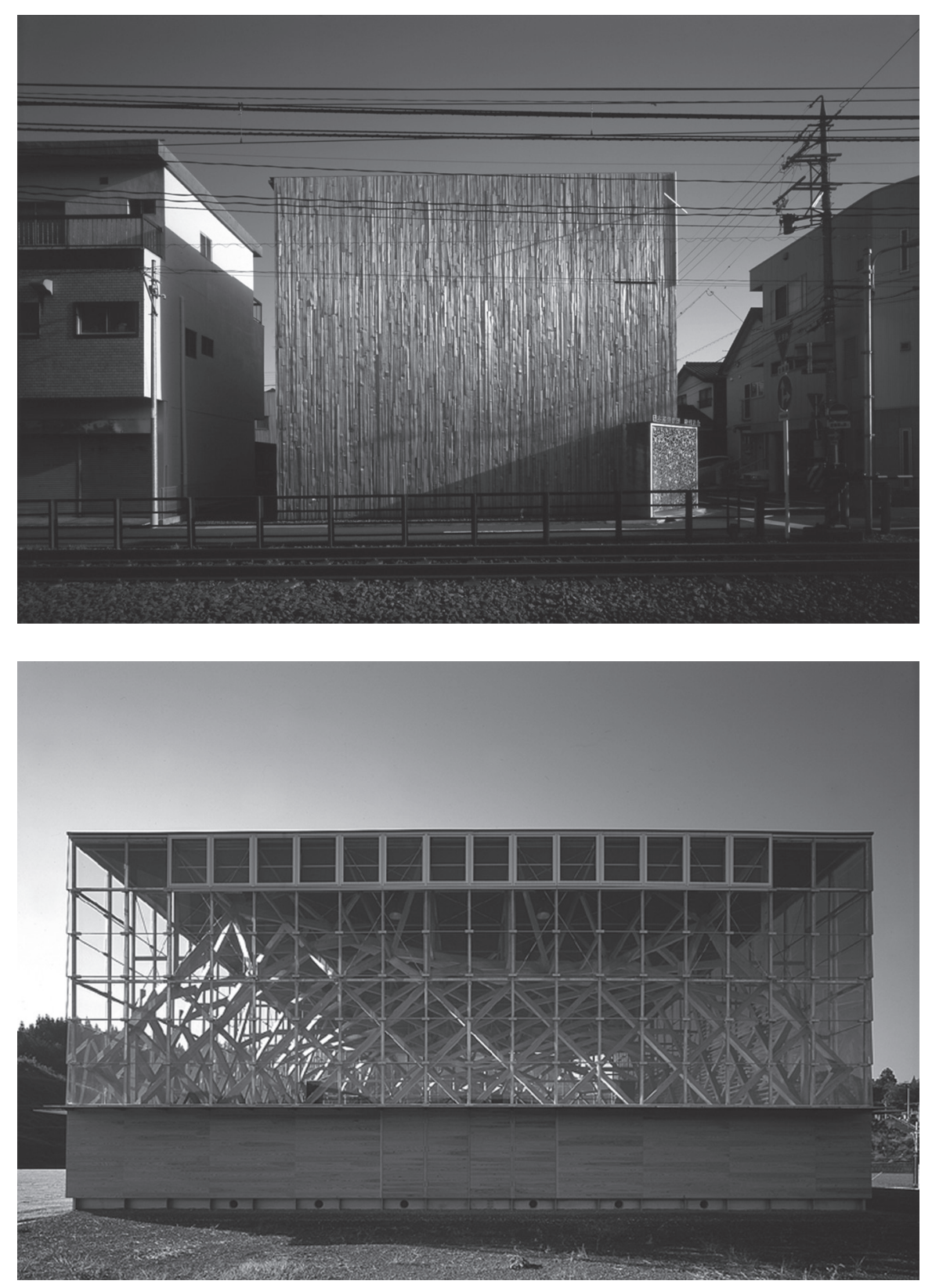

Church Sun-Pu, Shizuoka (2008). Taira Nishizawa Architects. [Photo: Hiroshi Ueda]

Fig. 4 Forest Hall, To-mochi, Kumamoto (2004). Taira Nishizawa Architects. [Photo: Hiroshi Ueda] 
Forest Hall plan and section, To-mochi,

Kumamoto (2004). Courtesy of Taira

Nishizawa Architects
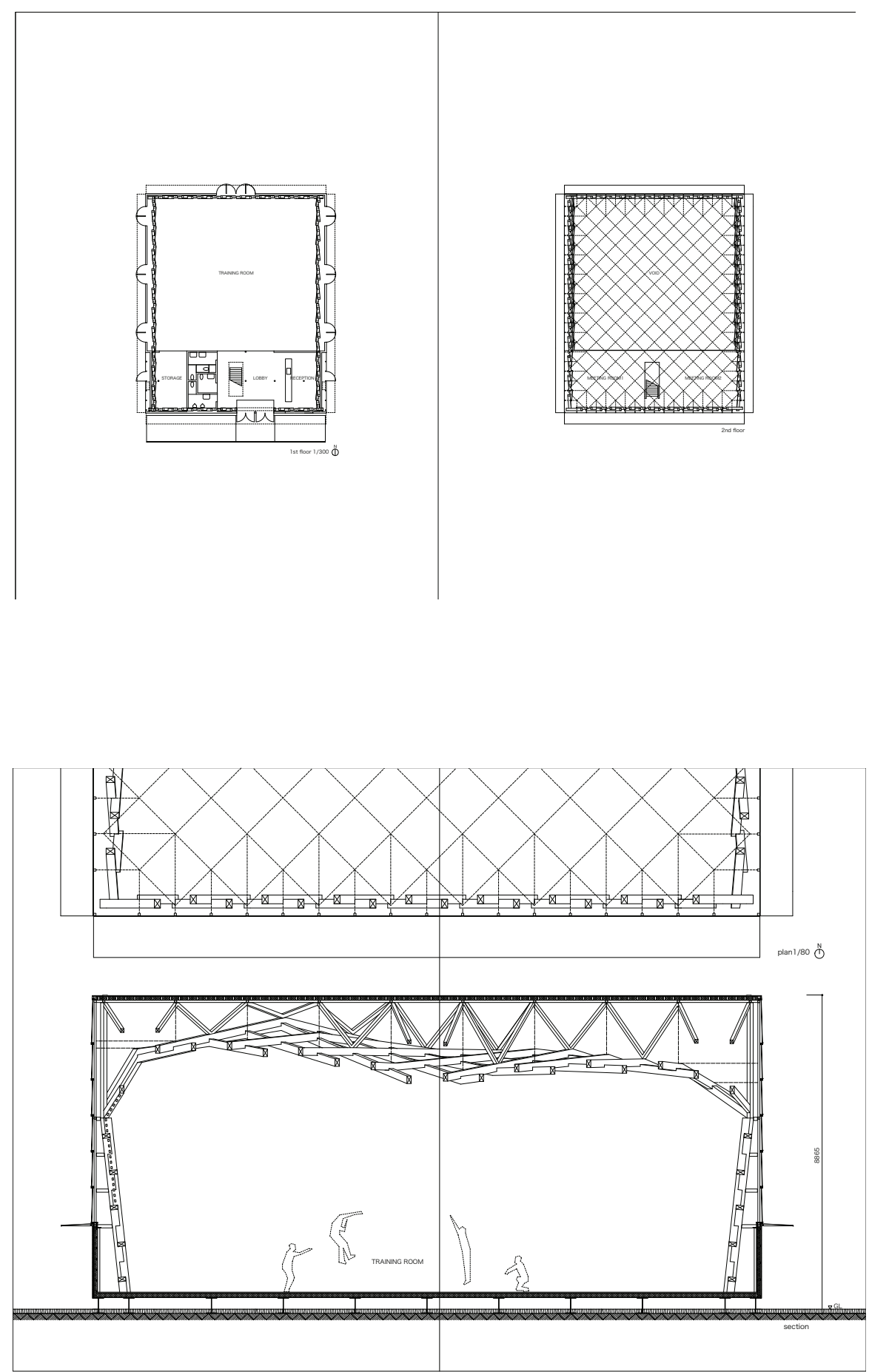